
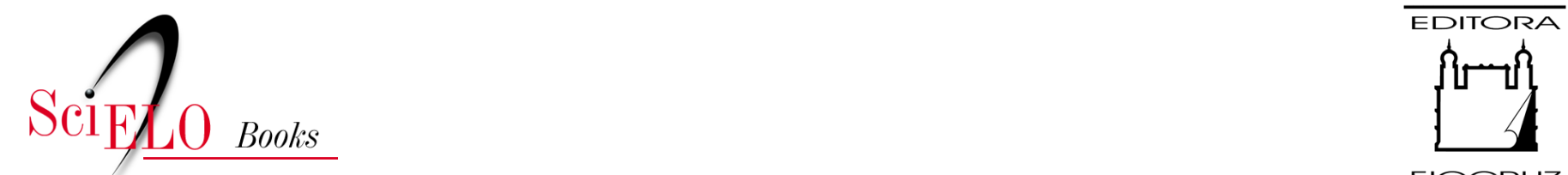

$\underline{\text { FIOCRUZ }}$

\title{
Clássicos \& Comentários 9-Emmanuel Dias \& José Pellegrino - Alguns ensaios com o 'Gamexanne' no combate aos transmissores da doença de Chagas.
}

\author{
José da Rocha Carvalheiro \\ Nara Azevedo \\ Tania C. de Araújo-Jorge \\ Joseli Lannes-Vieira \\ Maria de Nazaré Correia Soeiro \\ Lisabel Klein \\ (orgs.)
}

\section{SciELO Books / SciELO Livros / SciELO Libros}

CARVALHEIRO, J. R., AZEVEDO, N., ARAÚJO-JORGE, T. C., LANNES-VIEIRA, J., SOEIRO, M. N. C., and KLEIN, L., eds. Emmanuel Dias \& José Pellegrino - Alguns ensaios com o ‘Gamexanne' no combate aos transmissores da doença de Chagas. In: Clássicos em Doença de Chagas: histórias e perspectivas no centenário da descoberta [online]. Rio de Janeiro: Editora FIOCRUZ, 2009, pp. 333-360. ISBN: 978-65-5708-101-3. https://doi.org/10.7476/9786557081013.0014.

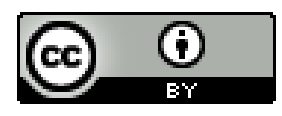

All the contents of this work, except where otherwise noted, is licensed under a Creative Commons Attribution 4.0 International license.

Todo o conteúdo deste trabalho, exceto quando houver ressalva, é publicado sob a licença Creative Commons Atribição 4.0.

Todo el contenido de esta obra, excepto donde se indique lo contrario, está bajo licencia de la licencia Creative Commons Reconocimento 4.0. 


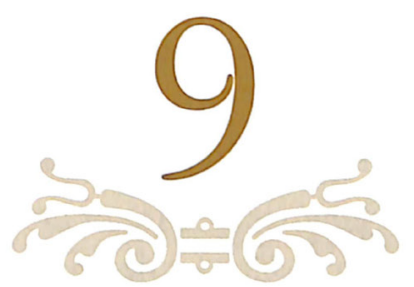

G Mmanuel DiAs \& José PELLEGRINo Alguns ensaios com o 'Gamexanne' no combate aos transmissores da doença de Chagas. Separata de Brasil Médico, (18-20): 1-20, 1948. 


\section{Emmanuel Dias (1908-1962)}

Médico nascido no Rio Janeiro, foi diretor do Centro de Estudos e Profilaxia da Moléstia de Chagas de Bambuí e destacou-se pela realização de importantes investigações científicas sobre a tripanossomíase americana e pelas primeiras ações de controle da doença.

\section{José Pellegrino (1922-1977)}

Sanitarista mineiro, desenvolveu pesquisas em Bambuí sobre a profilaxia da doença de Chagas. Foi professor da Universidade Federal de Minas Gerais e pesquisador do Instituto de Pesquisas René Rachou, que passou a integrar a Fundação Oswaldo Cruz em 1970. 


\section{BRASIL-MEDICO}

SEPARATA

Tlguns ensaios com o "Gammexane" no combate aos transmissores da Doenca de Chagas

EMMANUEL DIAS e J. PELLEGRINO

"Separate" do BRASIL-MEDICO, Ano LXII, Ns, 18, 19 e 20 de 1,8 e 15 de Maio de 1948

S. D R E C IA.

Ree Rodrigo silve, $14-30^{\circ}$

Tel. 22-1250 - Rio do Janeiro 


\title{
ALGUNS ENSAIOS COM O "GAMME- XANE" NO COMBATE AOS TRANSMIS- SORES DA DOENCGA DE CHAGAS (*)
}

\author{
EMMANUEL DIAS e J. PELLEGRINO
}

Em vista dos notáveis resultados obtidos com o "Gammexane" (isômero gama do hexacloroclclohexana) no extermínio de insétos e outros artrópodos nocivos, empreendemos no Centro de Estudos e Profilaxia da Doença de Chagas, do Instituto Oswaldo Cruz, em Bambuí, Minas Gerais, ensaios contra os triatomas, valendo-nos do ensejo que nos proporcionou a visita do Snr. G. L. Windred, da Imperial Chemical Industries, que nos forneceu material para o inicio dos trabalhos, aos quais assistiu.

A seguir relatamos algumas. das experiências feitas no laboratório e em cafúas infestadas, quase todas com o "Gammexane P 530" ou pó molhável que contém cerca de $6,5 \%$ do isômero gama. Nos ensaios de laboratório procurámos aproximar-nos o mais possivel das condições em que o inseticida tem que ser empregado na prática, utilizando-nos de superfícies de barro tratadas com o produto, afim de verificar seu poder tóxico imèdiato e residual.

1) - Uma superfície de barro lisa, de $120 \mathrm{~cm}^{2}$. foi fina e regularmente pulverizada (bomba de De Vilbiss) com uma suspensão de "Gammexane P 530", de modo que a concentração de isômero gama correspondesse a $2 \mathrm{gr}$. por $\mathrm{m}^{2}$. Ao todo 181 T. infestans (31 adultos, 155 ninfas e larvas), em pequenos lotes, permaneceram em contacto com essa superfície durante 1 minuto, sendo a seguir separados em vidros e observados, a inter-

(2) Trabalho da Divisão de Estudos de Endemias do Instituto Oswaldo Cruz. 


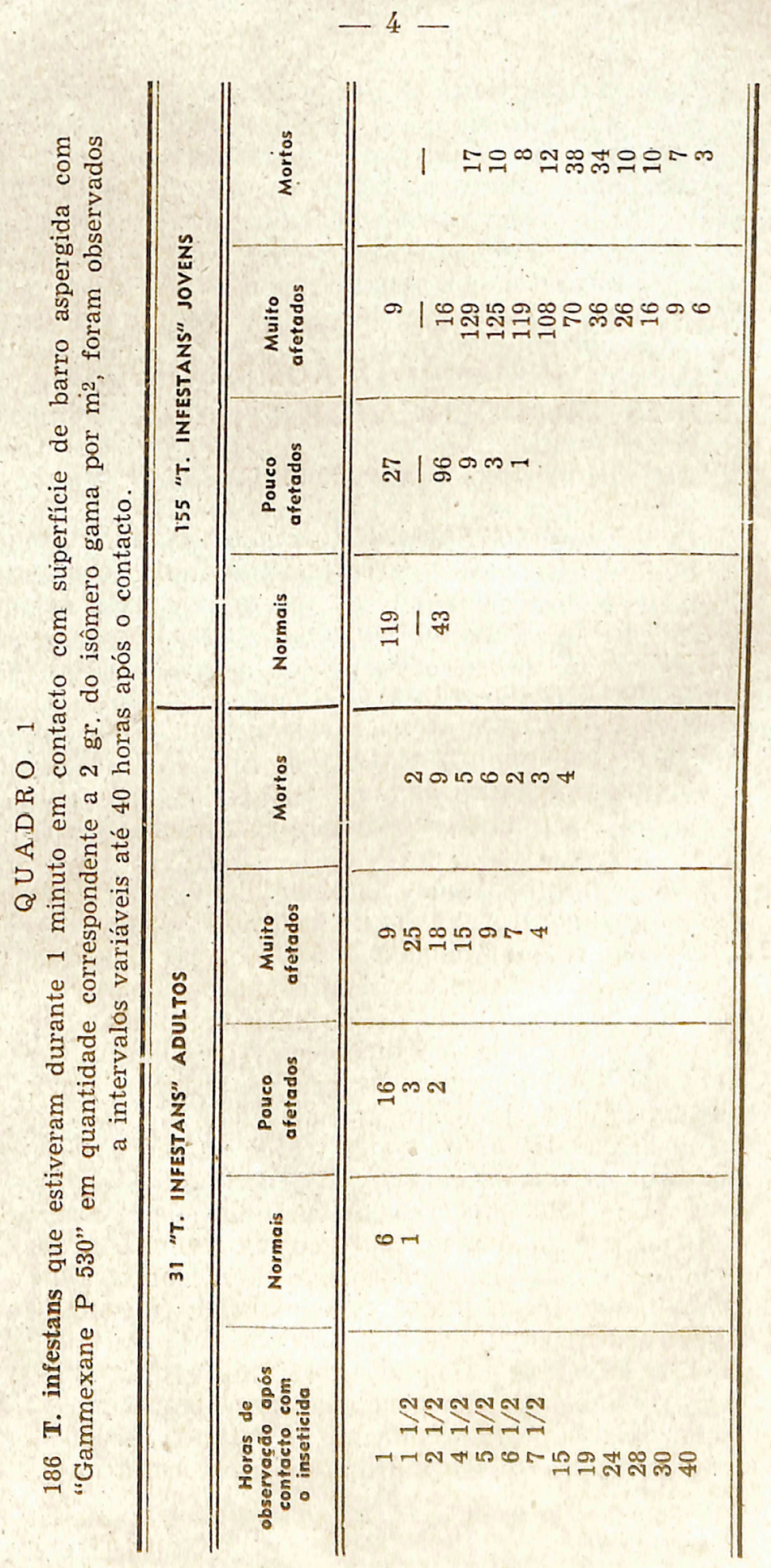


valos variáveis, até 40 horas depois. Os resultados estão no quadro 1. Todos os adultos estavam mortos ao fim de 15 horas e apenas 6 ninfas estavam vivas, muito afetadas, ao fim das 40 horas:

2) - Uma parede de barro semelhante à das cafúas, de $1665 \mathrm{~cm}^{2}$ de superfície e de $9 \mathrm{~cm}$. de espessura, foi construida numa armação de madeira medindo 45 por 37 por $18 \mathrm{~cm}$. Um de seus lados sofreu pulverização com o poó molhável de maneira a ser obtida a concentração de $2,1 \mathrm{gr}$. de isômero gama por $\mathrm{m}^{2}$. A armação foi fechada com tela de ambos os lados, sendo deixados sôbre a superfície não aspergida $93 \mathrm{~T}$. infestans adultos e jovens. Encostado à tela do lado com inseticida ficou amarrado, do lado de fora, durante 3 noites, um frango, afim de atraír os barbeiros, que poderiam passar de um lado para outro pelas fendas da parede. Duas horas depois de iniciada a experiência já se viam barbeiros adultos caídos, afetados. Ao fim de 60 horas desmanchou-se a parede para verificação dos resultados, que se acharm no Quadro 2: dos 65 adultos, 61 estavam mortos, 4 muito afetados; das 28 formas jovens, estavam mortas 9, muito afetadas 13 e normais 6 .

A notar que 43 insetos mortos e muito afetados foram achados dentro da parede e 44 mortos estavam caídos ao chão. Fato semelhante seguramente ocorrerá nos expurgos feitos nas cafúas.

$$
\text { QUADRO } 2
$$

93 T. infestans foram deixados no lado não tratado de uma parede de barro fendida, sendo atraídos para o lado opôsto que foi pulverizado com 2,16 gr. de isômero gama por $\mathrm{m}^{2}$; a parede foi desmanchada 60 horas depois para verificação dos resultados.

\begin{tabular}{|c|c|c|c|c|c|}
\hline \multirow{3}{*}{\multicolumn{2}{|c|}{$\begin{array}{l}\text { Estadio evolutivo } \\
\text { e n.0 de barbeiros } \\
\text { empregados }\end{array}$}} & \multicolumn{4}{|c|}{ Ao cabo de 60 horas: $n 0^{\circ}$ de barbeiros } \\
\hline & & \multirow{2}{*}{ No chão } & \multicolumn{3}{|c|}{ No interior da parede } \\
\hline & & & Mortos & $\begin{array}{l}\text { Muito } \\
\text { afetados }\end{array}$ & Normais \\
\hline Machos & 32 & 18 & 11 & 3 & 0 \\
\hline Femeas & 33 & 17 & 15 & 1 & 0 \\
\hline Ninfas & 17 & 7 & 0 & 5 & 5 \\
\hline Larvas & 11 & 2 & 0 & 8 & 1 \\
\hline Total & 93 & 44 & 26 & 17 & 6 \\
\hline
\end{tabular}


3) - Verificação da toxidez imediata e residual do Gammexane. Três caixas de madeira de 20 por 20 por $15 \mathrm{~cm}$., internamente envidraçadas, receberam uma camada de barro misturado com estrume, de superfície lisa medindo $400 \mathrm{~cm}^{2}$. Seco o barro, procedeu-se à borrifação, por meio de seringa munida de agulha fina, o mais regular possivel, do inseticida contido em 10 a 12 ce. dágua, de maneira quê as três superfícies receberam respectivamente $1 \mathrm{gr}$., $2 \mathrm{gr}$. e $3 \mathrm{gr}$. do isômero gama por metro quadrado. 0 líquido era ràpidamente absorvido, ficando as superfícies secas em pouco tempo. Lotés de T. infestans foram deixados nas caixas durante 5 e 15 minutos, procurando-se fazer com que constantemente ficassem em movimento sôbre o barro. Um mês e dois meses depois de aspergidas as caixas foram novamente usadas nas mesmas condições, tendo permanecido à temperatura ambiente, ao abrigo de poeira. Os barbeiros de cada lote foram conservados separadamente em vidros e observados cada dia, retirando-se os mortos e anotando-se as condicóes dos sobreviventes. Os resultados constam dos quadros 3-4-5 após cuja análise parecem cabíveis, entre outras, as seguintes apreciações: a) a mortalidade foi de $100 \%$ sòmente nos lotes de barbeiros que estiveram em contacto com a superfície com $3 \mathrm{gr}$. de isômero gama por metro quadrado, logo depois de aspergida; b) ao fim de 1 mês as superfícies de barro tratadas haviam perdido bôa parte de sua toxicidade; ao fim de 2 meses ainda havia ação residual, evidenciável pela exposição dos triatomas por tempos bem superiores aos inicialmente empregados; c) com o correr do tempo a atividade do inseticida vai se manifestando mais tardiamente; d) a ação tóxica das superfícies que receberam 2 e 3 gr. por $\mathrm{m}^{2}$ tornou-se pràticamente equivalente (quadros 4-5); e) a ação do Gammexane é mais pronunciada sôbre os adultos do que sôbre as formas jovens de T. infestans, conforme também o demonstram as demais experiências.

4) - Para verificação comparativa da ação tóxica do Gammexane e a do DDT, e a de ambos associados, foram preparadas três caixas de madeira iguais às usadas em (3), sendo cada uma delas aspergida com (a) 0,5 gr. de isômero gama 


$$
\begin{aligned}
& -7-
\end{aligned}
$$

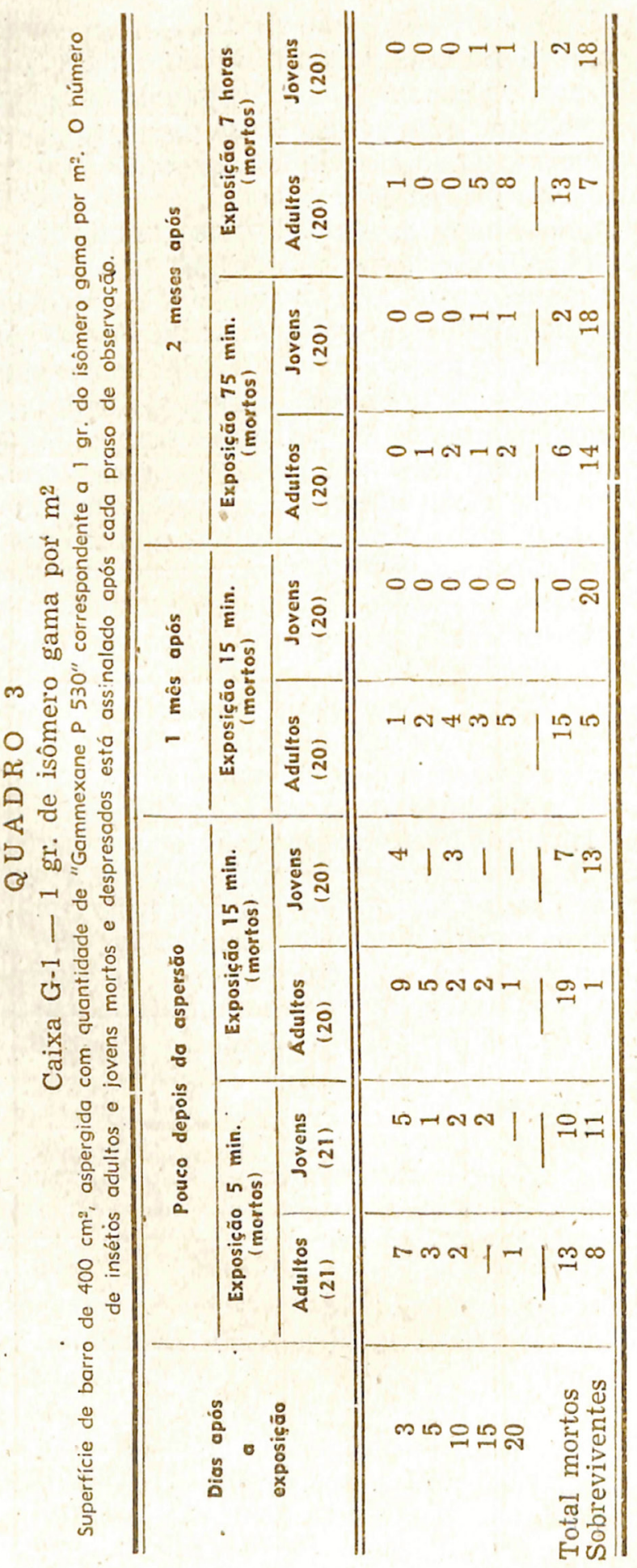




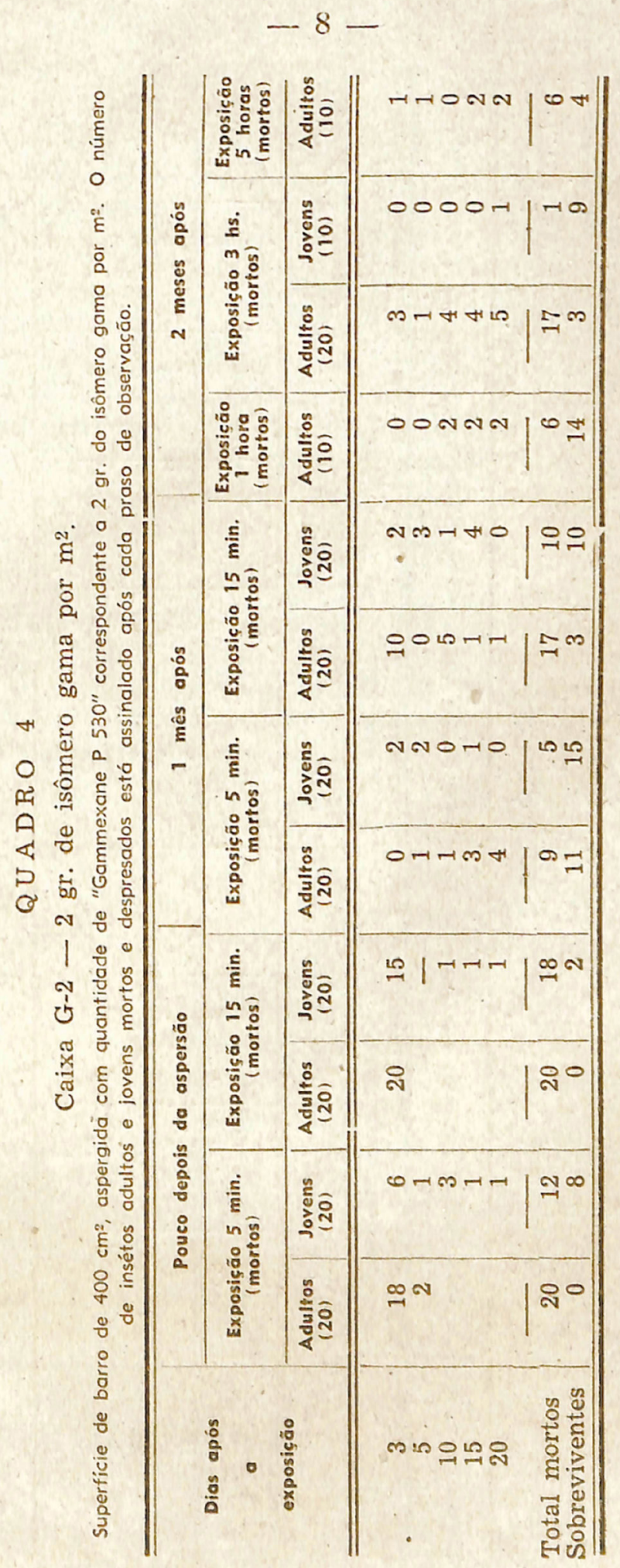




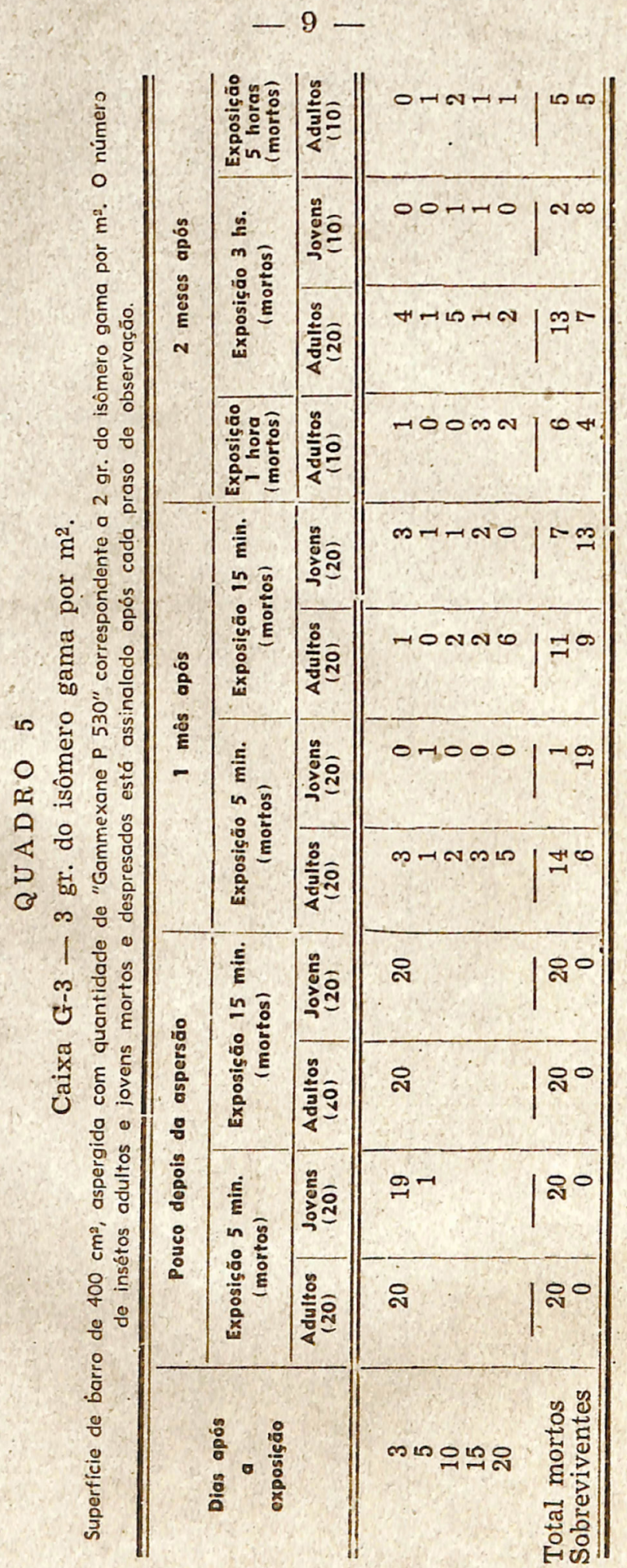




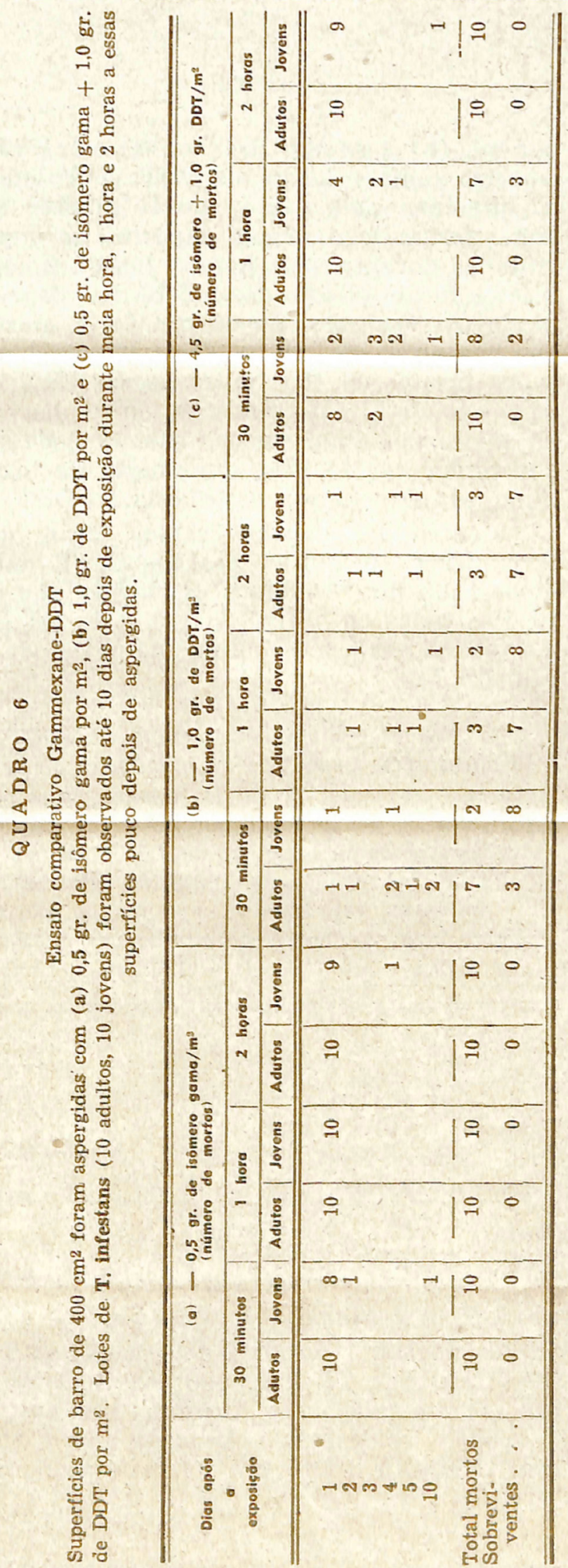


por $\mathrm{m}^{2}$, (b) $1 \mathrm{gr}$. de DDT por $\mathrm{m}^{2}$ e (c) $0,5 \mathrm{gr}$. de isômero gama $+1,0 \mathrm{gr}$. de DDT. Três lotes de 20 T. infestans cada um, sendo 10 adultos e 10 jovens, foram logo depois expostos às superfícies tratadas durante meia hora, 1 hora e 2 horas. Os insetos foram observados até 10 dias depois, constando os resultados do quadro 6. A mortalidade dos barbeiros de (a) foi de $100 \%$, enquanto que a dos insetos de (b) foi de apenas $33 \%$ e a dos de (c) foi de 91,6\%. Em vista do pequeno número de triatomas empregados, não se pode concluir que tenha havido uma diminuição da toxidez do Gammexane pela sua associação ao DDT.

Dentro das mesmas caixas foram deixados permanecer 10 ninfas grandes de T. infestans, sendo cada dia recolhidos os mortos. Ao cabo de 10 dias todas as ninfas de (a) e de (c) estavam mortas, ao passo que 8 ninfas de (b) ainda viviam (quadro 7).

\section{QUADRO 7}

Ensaio comparativo Gammexane-DDT

48 horas após a aspersão de superfícies de barro de $400 \mathrm{~cm}^{2}$ : (a) com 0,5 gr. de isômero gama por $\mathrm{m}^{2}$, (b) com 1,0 gr. de DDT por $\mathrm{m}^{2}$ e (c) com $0,5 \mathrm{gr}$. de isômero gama $+1,0 \mathrm{gr}$. de DDT por $\mathrm{m}^{2}$, foram deixados em cada uma 10 ninfas grandes de $\mathbf{T}$. infestars, retirando-se.cada dia os mortos.

\begin{tabular}{c|r|r|r}
\hline DIAS & (a) & (b) & (c) \\
\hline 1 & 5 & 0 & 9 \\
2 & 4 & 0 & 0 \\
3 & 1 & 0 & 1 \\
ao cabo de 10 dias & - & 2 & - \\
Mortos $\ldots \ldots \ldots \ldots$ & 10 & 2 & 10 \\
\hline
\end{tabular}

Vê-se assim que o Gammexane tem ação muito superior à do DDT em relação ao $\mathbf{T}$. infestans, fato este já observado por Busvine \& Barnes (1) em relação ao Rhodnius prolixus.

5) - Na parede interna de uma cafúa feita com tijolos de barro crú foi delimitada uma su- 
perfície de meio metro quadrado, que foi finamente e regularmente pulverizada (bomba manual) com Gammexane P $530 \mathrm{em}$ quantidade correspondente a $2 \mathrm{gr}$. de isômero gama por $\mathrm{m}^{2}$. A pulverização foi feita de maneira a quase não haver absorção de líquido pelo barro, ficando aparentemente todo o inseticida na superfície, que se tornou esbranquicada. Um mês e dois meses depois foram deixados em contacto com ela, durante meia hora e 1 hora respectivamente, dois lotes de 20 T. infestans, sendo 10 jovens e 10 adultos. C quadro 8 mostra que após 10 dias de observação

\section{QUADRO 8}

Ação residual do Gammexane. Superfície de parede de cafúa, interna, de $0,5 \mathrm{~m}^{2}$, foi finamente pulverizada com $1 \mathrm{gr}$. de isômero gama ( $=2,0$ gr. por $\mathrm{m}^{2}$ ). Um mês depois da aspersão 20 T. infestans ficaram meia hora em contacto com a superfície e dois meses depois da pulverização outros 20 estiveram durante 1 hora em contacto com a mesma. Os insetos foram observados até 10 dias, sendo os mortos contados e separados.

\begin{tabular}{c|r|r|r|r}
\hline \multirow{2}{*}{$\begin{array}{c}\text { Dios após } \\
\text { a exposiçấo }\end{array}$} & \multicolumn{2}{|c|}{1 mês $-1 / 2$ hora } & \multicolumn{2}{|c|}{2 meses -1 hora } \\
\cline { 2 - 5 } & adultos & jovens & adultos & jovens \\
\hline 1 & 2 & 0 & 2 & 1 \\
2 & 4 & 1 & 0 & 1 \\
5 & 2 & 0 & 6 & 4 \\
10 & 2 & 2 & 2 & 1 \\
Total de mortos & 10 & 3 & 10 & 7 \\
\hline \hline
\end{tabular}

dos insetos todos os adultos estavam mortos, havendo sobrevivido algumas formas jovens.

6) - Na localidade de Santa Juliana (Triângulo Mineiro) foram escolhidas ao acaso 8 cafúas com vestígios de barbeiro, em algumas das quais foram feitas capturas prévias. As paredes internas foram aspergidas com Gammexane P 530 (1 kg. em 18 litros dágua; ao pó juntava-se pequeno volume dágua, misturava-se bem, passava- 


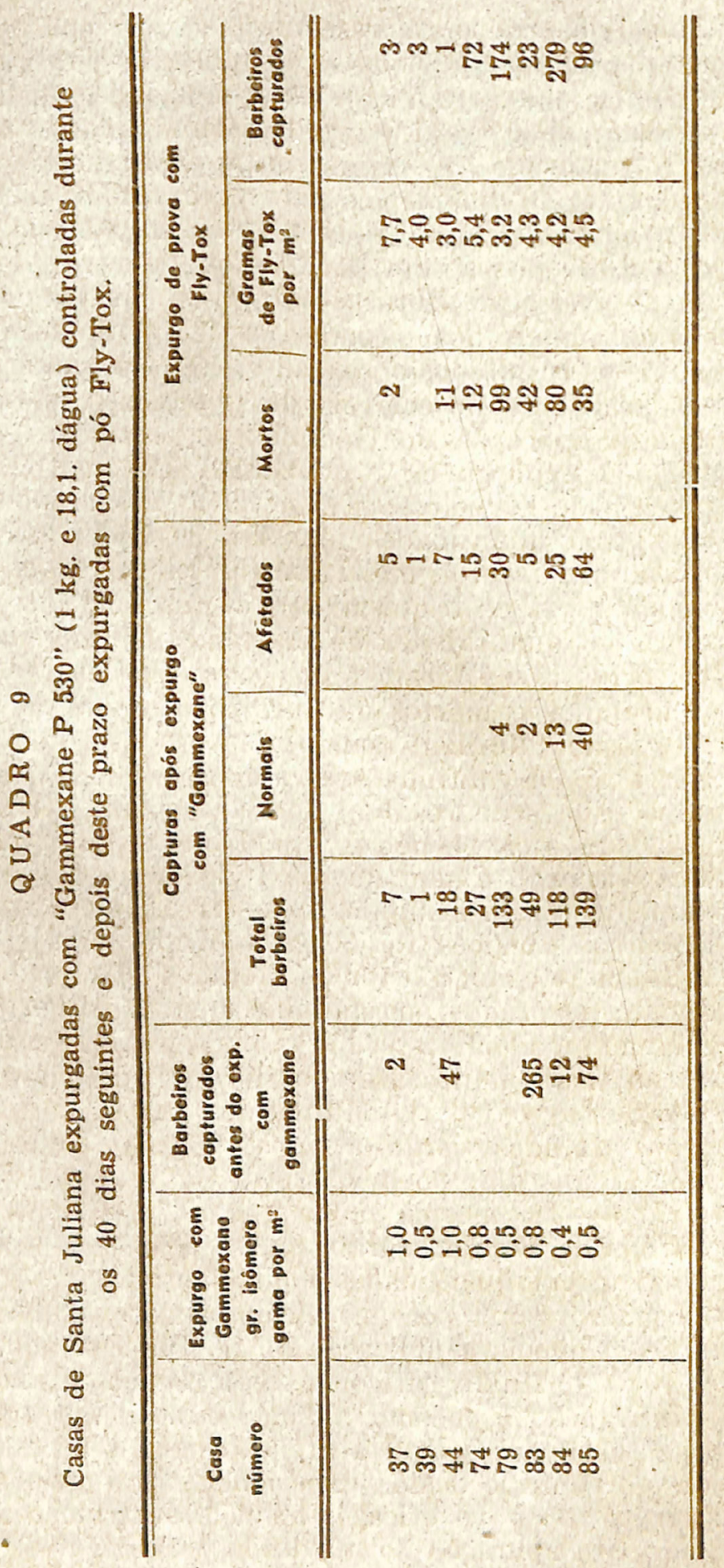


se em tela e depois acrescentava-se aos poucos o restante dágua, fazendo-se a aplicação por meio de bomba aspersora Vita). As quantidades usadas variaram de 0,4 e $1,0 \mathrm{gr}$. do isômero gama por metro quadrado. As casas foram diàriamente visitadas até 40 dias depois para procura de barbeiros e outros insetos. Foram então submetidas a expurgo de prova com pó Fly-Tox (piretro), que tem notável ação sôbre os barbeiros, desalojandoos prontamente dos esconderijos (2). 0 quadro 9 resume os resultados observados. Se bem que houvesse capturas apreciáveis de triatomas, em seguida à aplicação do Gammexane, em todas as cafúas o expurgo de prova ainda demonstrou a presença de barbeiros. Em geral as casas expurgadas com quantidades menores de Gammexane forneceram insetos mais abundantes ao expurgo com pó Fly-Tox, o que mostra terem sido insuficientes as quantidades de inseticida empregadas. $\mathrm{Em}$ certos casos foram feitas capturas de barbeiros afetados e mortos durante todo o período de observação (40 dias), sendo pois provável que os insetos ainda continuassem a morrer além deste tempo, pela ação residual do Gammexane. O número total dos barbeiros apanhados após o primeiro expurgo é sem dúvida inferior ao dos que realmente foram atingidos, pois nessas e em muitas outras ocasiões foi observado que os insetos que cáem ao chão, mortos ou afetados, são imediatamente devorados por galinhas que os procuram ávidamente; além disto, há os barbeiros que morrem ou ficam muito afetados no interior das paredes de barro (v. 2). Muitos dos barbeiros apanhados afetados vieram a morrer depois de observados alguns dias no laboratório.

7) - Do mesmo modo que as precedentes, 7 cafúas de Bambuí foram expurgadas com o pó molhável, em quantidades equivalentes a 1,0 gr. do isômero gama por $\mathrm{m}^{2}$. A intervalos variáveis sofreram depois a aplicação do pó Fly-Tox (quadro 10). Ao final verificou-se uma redução grande da infestação e mesmo a sua extinção em três casas. Chamamos aqui a atenção para a necessidade do contrôle destas experiências por meio de expurgos de prova eficazes ou pela destruição da cafúa para apuração do resultado definitivo. 
8) - Ação sôbre os ovos - Vários ovos de T. infestans em diversas fases foram deixados sôbre uma superfície de barro que recebeu $2 \mathrm{gr}$. de isômero gama por $\mathrm{m}^{2}$, verificando-se em todos desalagamento normal. As larvas morreram depois de entrarem em contacto com a superfície.

9) - "Smoke generators". Foi feita uma única experiência, numa pequena cafúa de Bambuí de volume aproximado de $40 \mathrm{~m}^{3}$, na qual já haviam sido capturados muitos triatomas. Orifícios e fendas das paredes e entre a parede e o teto foram obstruídos com papel. No interior foram queimados 3 geradores de fumo n. ${ }^{\circ} 2$ (cada um pesa $56 \mathrm{gr}$. e contém cêrca de $9,7 \%$ de isômero gama) que queimaram pela metade. A casa ficou fechada durante pouco mais de 1 hora. No dia seguinte foram capturados 4 adultos e 8 jovens vivos e 6 jovens mortos (T. infestans). Dois dias após o expurgo foi feito expurgo de prova com pó FlyTox (600 gr.) sendo capturados mais de 300 T. infestans em todas as fases evolucivas. Os moradores disseram que depois da casa aberta permaneceu por várias horas um cheiro ativo e todos se queixaram de cefaléia.

Nestas condições o resultado da aplicação do "smoke generator" foi ineficiente, mas novos ensaios são necessários, em face dos bons resultados com êle obtidos por Romaña e Abalos (3) na Argentina. No nosso ensaio houve muito pouco tempo para poder ser apreciada a provável ação residual do inseticida, mas de qualquer maneira a percentagem de insetos mortos foi extremamente baixa. Parece que na prática é preferivel o expurgo com o pó molhável ao uso do gerador de fumo.

9) - Expurgo combinado Gammexane-Piretro - Uma cafúa muito infestada de Bambuí, na qual dias antes fora feita uma captura manual de 4 adultos e 48 formas jovens de T. infestans, foi submetida a várias provas. Inicialmente, a título de experiência, fez-se num quarto a aspersão (De Vilbiss) com $200 \mathrm{cc}$. de "emulsifiable Pyrenone 10-1" (piretro) a $1: 40$, que provocou a saída de $92 \mathrm{~T}$. infestans (23 adultos, 69 jovens) os quais nos dias subsequentes morreram na quase 
totalidade. A seguir foi feita a aplicação de Gammexane P $530 \mathrm{em}$ todas as dependências na proporção de $2,3 \mathrm{gr}$. por $\mathrm{m}^{2}$, que não determinou o aparecimento de triatomas. Imediatamente depois foram pulverizadas nas frestas 400 gr. de pó FlyTox, saindo 120 T. infestans e grande número de baratas que foram devoradas, bem como muitos barbeires não computados, pelas galinhas que invadiram a casa. Nos dias imediatos os moradores enviaram 6 adultos e $21 \mathrm{~T}$. infestans jovens. Nove dias após o expurgo foi feita primeira prova e 59 dias após segunda prova com Fly-Tox (respectivamente 800 e $600 \mathrm{gr}$.) : as capturas foram de 5 adultos e 16 jovens na primeira e de apenas 2 larvas novas na segunda.

O emprego associado de Gammexane e piretrinas tem a grande vantagem de produzir uma grande baixa imediata do número de insetos, aliando-se a ação tóxica residual de um à ação imediata das outras, tendo entretanto o inconveniente do aumento do custo.

\section{CONSIDERAÇÕES FINAIS}

Baseados nos resultados descritos podemos fazer algumas considerações acêrca do emprego do "Gammexane" contra os triatomas, das quais as de maior interesse são as que se seguem.

$\mathrm{O}$ produto sob a forma de "Gammexane P 530 " (pó molhável) é o que parece ser mais aconselhável na prática, na proporção de 1 a 2 gramas de isômero gama por metro quadrado. É mais recomendável a pulverização o mais fina possível para ser obtida maior concentração do inseticida na superfície do barro que absorve muito líquido quando grosseiramente aspergido.

Como inseticida de ação residual, é o que melhores resultados tem proporcionado. Após 1 mês há uma queda sensível do poder tóxico, mas este pode durar até pelo menos 2 meses. Revelou-se bem superior ao DDT. A ação tóxica é bem mais pronunciada sôbre os barbeiros adultos do que sôbre as formas jovens, não se exercendo sôbre os ovos. Por isso e por decair com o tempo a ação residual, deve ser recomendada a repetição dos 
expurgos domiciliares com 1 ou 2 meses de intervalo.

O "Gammexane" (pó molhável), não tendo ação repelente ou irritante sôbre os barbeiros e não determinando sua saída dos esconderijos dentro das paredes, com vantagem pode ser aplicado em expurgos mixtos com o pó de piretro, que a possue em grau acentuado; a aplicação combinada torna mais ràpida e mais completa a destriatomização das cafúas.

Embora não seja o produto ideal pelas suas propriedades e pelo seu custo, não resta dúvida que o Gammexane constitue um novo recurso de valor para a luta contra os transmissores da doença de Chagas.

\section{REFERENCIAS}

1 - J. R. Busvine \& S. Barnes - Observations on mortality among insects exposed to dry insecticidal films - Bull. Entom. Res., vol. 38, parte 1, p. 81, 1947.

2 - E. Dias - Profilaxia da doença de Chagas Brasil-Medico, vol. 60: 161-163, 1946.

3 - Romaña, C. \& J. Abalos - Acción de los generadores de humo a base de "Gammexane" sobre los triatomideos y otros artropodos - Nota prévia. Comunicação lida na reunião de 18-4-1947 da Soc. de Biol. de Tucuman, Argentina. Copia mimeogra. fada, 4 págs. 


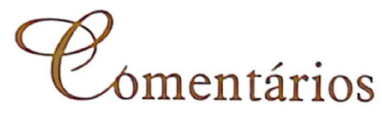

\title{
Reflexões sobre 'Alguns ensaios com o Gammexane no combate aos transmissores da doença de Chagas', de Emmanuel Dias e José Pellegrino, 1948: conquistas e desafios no contexto da diversidade triatomínica, cem anos após a descoberta da tripanossomíase americana
}

\author{
Fane Costa \\ Carlos Eduardo Almeida \\ Laboratório de Biodiversidade Entomológica \\ Instituto Oswaldo Cruz/Fiocruz \\ Cleber Galvão \\ Laboratório Nacional e Internacional de Referência em Taxonomia de Triatomíneos \\ Instituto Oswaldo Cruz/Fiocruz
}

Até a descoberta da doença de Chagas em 1909, 57 espécies de triatomíneos já eram conhecidas; entretanto, as descrições feitas por vários naturalistas europeus nessa época restringiam-se aos seus aspectos morfológicos superficiais, não havendo estudos específicos sobre as características biológicas desses insetos hematófagos encontrados principalmente na América do Sul. A descoberta da tripanossomíase americana chamou a atenção para a importância dos triatomíneos; várias outras novas espécies foram descritas, e tais descrições, publicadas em várias revistas científicas, incluindo também seus ciclos biológicos e a caracterização de seus ambientes naturais (Neiva, 1910). Em 1979, 111 espécies já haviam sido descritas e sumarizadas em uma das mais notórias contribuições já apresentadas para o grupo dos triatomíneos (Lent \& Wygodzinsky, 1979). Atualmente, existem 140 espécies reconhecidas de vetores da doença de Chagas (Galvão et al., 2003; Forero, Weirauch \& Baena, 2004; Costa, Argolo \& Félix, 2006; Galvão \& Ângulo, 2006; Costa \& Félix, 2007; Bérenger \& Blanchet, 2007; Martinez et al., 2007; Sandoval et al., 2007); deste total, 61 espécies ocorrem no Brasil, país onde se concentra a maior diversidade em termos de triatomíneos (Galvão et al., 2003; Costa et al., 2003). As espécies vetoras podem ser encontradas em quase toda a extensão da América Latina e parte da América do Norte. Apenas o gênero Linshcosteus 
Distant, 1904 é endêmico do Velho Mundo, sendo encontrado exclusivamente na Índia (Lent \& Wygodzinsky, 1979). Outra exceção é Triatoma rubrofasciata De Geer, 1773, a primeira espécie de triatomíneo descrita. Trata-se de um inseto pantropical que habita principalmente áreas portuárias, onde está associado à presença de roedores. Esse triatomíneo é freqüentemente encontrado infectado por T. conorrhini, que não é patogênico para o homem (Deane, 1947). Os primeiros registros sobre aspectos biológicos dos triatomíneos foram realizados por Reginaldo de Lizárraga em 1590, em regiões do Peru e do Chile (Galvão et al., 2003).

Estudos indicam que a tripanossomíase americana vinha se mantendo restrita ao ambiente silvestre no continente americano, pois evidências obtidas até então sugerem que no período pré-colombiano os triatomíneos habitavam apenas os ninhos de vertebrados em seus ecótopos naturais, antes de o Brasil ser colonizado por europeus e africanos (Lent \& Wygodzinsky, 1979). Entretanto, mais recentemente, múmias encontradas no Peru, no Chile e em Minas Gerais mostram que a doença de Chagas já vinha ocorrendo em comunidades de coletores e caçadores há pelo menos 4.500-7.000 anos. A disseminação da endemia, porém, ocorreu em época bem mais recente, originária de grandes movimentos populacionais, alcançando os picos de endemicidade na primeira metade do século XX (Silva, 1985; Lima et al., 2008).

Nesse período, nas áreas endêmicas os vetores eram bem conhecidos pela população local, especialmente Triatoma infestans Klug, 1834, Panstrongylus megistus Burmeister, 1835, Triatoma brasiliensis Neiva, 1911, Triatoma sordida Stål, 1859 e Triatoma pseudomaculata Corrêa e Espínola, 1964, devido principalmente à alta densidade populacional em que ocorriam no intradomicílio em certas áreas (Dias \& Zeledon, 1955). Acredita-se que o principal vetor da doença no Brasil, T. infestans, tenha sido introduzido por transporte passivo, a partir dos vales do Cochabamba, na Bolívia, em decorrência das grandes migrações durante os ciclos da agricultura e da pecuária, sendo, portanto, considerado uma espécie introduzida, já que não existem registros de seu encontro em ecótopos naturais nesse país. A situação calamitosa das infestações domiciliares por T. infestans nas áreas rurais levou um grupo de cientistas a se empenhar em resolver e controlar a transmissão vetorial. Assim, um dos marcos no controle dessa endemia foi o trabalho de Emmanuel Dias e José Pellegrino publicado em 1948, demonstrando que, através de expurgos regulares de inseticida de ação residual, Gammexane, seria possível controlar as populações dos insetos vetores nos domicílios, local onde a transmissão vetorial ocorre. Toda a base técnica dessa campanha antitriatomínica já tinha suas linhas gerais delineadas na década de 1940, com a instalação de um posto do Instituto Oswaldo Cruz (IOC) em Bambuí, Minas Gerais, sob a orientação de Emmanuel Dias (Dias, 1946). Com metodologia objetiva, precisa e detalhada, esse projeto, inovador e executado com determinação, demonstrou ser exeqüível o controle vetorial domiciliar em larga escala, prognosticando a eliminação de T. infestans. Assim, foi possível eliminar o principal vetor em Bambuí, e logo depois o estado de São Paulo utilizou como modelo a mesma metodologia e realizou também uma campanha criteriosa e bem-sucedida (Freitas et al., 1959). Os resultados obtidos tiveram grande influência não só no Brasil (Marsden et al., 1994), mas também em outros países como a Argentina (Romaña \& Aballos, 1948) e o Chile (Neghme \& Schenone, 1962), que também seguiram as estratégias propostas por Dias e Pellegrino (1948).

Após os bem-sucedidos resultados, o principal desafio foi mobilizar as autoridades políticas em torno da importância da regularidade no tratamento químico das casas, o que impediria inúmeros casos de transmissão da doença. Desde o trabalho de Dias e Pellegrino (1948) até 1983, quando de fato teve início uma campanha de controle vetorial em nível nacional, passaram-se 35 anos. Durante esse período, campanhas de controle eram realizadas 
sem um enfoque que pudesse abranger todo o território brasileiro, e muitas vezes o contingente técnico era desviado para tratar do controle de outras endemias, principalmente a malária e a dengue. Finalmente, na campanha iniciada em 1983, cerca de dois mil municípios infestados por T. infestans foram tratados e monitorados. As bases técnicas de Dias e Pellegrino também serviram para a extensão do programa durante 15 anos, e finalmente, em 1999, mostrouse significativa a redução da transmissão vetorial no Brasil (Silveira \& Vinhaes, 1999), que culminou com a certificação da eliminação da transmissão vetorial por T. infestans em 2006 (Dias, 2006).

Os cenários de transmissão da doença de Chagas desde a sua descoberta em 1909 vêm apresentando mudanças nos seus contextos epidemiológicos, em decorrência, principalmente, das rápidas e drásticas mudanças ambientais. Hoje, diversas outras espécies até então consideradas estritamente silvestres vêm modificando seus comportamentos invasivos e se adequando às condições domiciliares: Triatoma vitticeps Stål, 1859, Triatoma rubrovaria Blanchard, 1843 e Panstrongylus lutzi Neiva e Pinto, 1923, entre outras, vêm apresentando colônias intradomiciliares com ampla mobilidade entre o ambiente silvestre e os ecótopos antrópicos (Gonçalves et al., 1998; Almeida et al., 2000; Souza et al., 2008; Freitas, Freitas \& Gonçalves, 2004). Mais recentemente, Triatoma sherlocki Papa et al., 2002 foi encontrada em área de mineração informal em Gentio do Ouro (região central noroeste da Bahia), formando colônias intradomiciliares (Almeida et al., 2009) em um cenário peculiar: uma área remota não alcançada pelo Programa de Controle da Doença de Chagas (PCDCH). Chamamos a atenção também para as crescentes infestações de outras espécies já bastante estudadas, tais como T. brasiliensis (Costa et al., 2003) nas áreas semi-áridas do Nordeste e T. sordida (Diotaiuti et al., 1995; Pelli et al., 2007), que, após as medidas para eliminar T. infestans, não têm recebido a devida atenção para monitoramento e controle.

Embora no Brasil as medidas para o controle vetorial visando principalmente à T. infestans tenham sido muito bem-sucedidas, nossa realidade requer um trabalho contínuo e determinado para que as condições propícias para a infestação domiciliar por triatomíneos sejam de fato modificadas (p. ex., substituição das casas de taipa por casas de alvenaria) e não se dependa unicamente da borrifação com inseticidas.

Como se pode observar, a história da doença de Chagas vem se transformando rapidamente diante das drásticas mudanças ambientais e sociais (Briceño-León \& Galván, 2007). Apesar dos relevantes avanços obtidos no controle dessa endemia, o risco de transmissão vetorial da doença de Chagas permanece, devido principalmente a dois fatores: (i) os vetores autóctones que vêm desafiando os órgãos de saúde após o controle de T. infestans; e, principalmente, (ii) a manutenção de precárias condições de moradia e educação em que ainda vive boa parcela da população rural.

Hoje, comemoram-se cem anos da descoberta dessa endemia, que sem dúvida foi um marco não só para a ciência biomédica no Brasil, mas no mundo. Apesar de toda a base técnica para o seu controle, a vontade política não acompanha a capacidade de torná-la efetiva. Essa questão foi muito bem enfocada por Coura (1993), que ressalta a defasagem entre o período em que foi demonstrada a exeqüibilidade do controle de Chagas com sólidas bases técnicas (Dias \& Pellegrino, 1948) e o início das campanhas propriamente ditas, em nível nacional. Sabemos que nossos desafios não são apenas políticos e econômicos. O Brasil é o maior país da América Latina, onde a diversidade não se restringe à fauna triatomínica, e apresenta também complexos contextos ecológicos e socioculturais. Continuam sendo reportadas invasões de domicílios por novas espécies de triatomíneos, cujos potenciais de transmissão ainda são 
desconhecidos (p. ex., Almeida et al., 2009). Na Amazônia, ainda muito pouco explorada, já se conhecem 18 espécies registradas (Coura, Barrett \& Naranjo, 1994). Devastação ambiental e migrações humanas cada vez mais intensas são também fatores que influenciam positivamente na manutenção e na dispersão da endemia chagásica (Briceño-León \& Galván, 2007).

Esperamos que em um futuro próximo, graças ao estudo visionário realizado em 1948 por Pellegrino e Dias, possamos comemorar a eliminação do risco vetorial, não somente por meio da aplicação de inseticidas ou da administração de drogas repelentes, mas principalmente pela melhoria das condições de moradia e mediante programas educacionais para o desenvolvimento de uma população rural saudável, atuante e crítica, que permita que de fato esse flagelo seja debelado. Esperamos que, no centenário que se segue, se exacerbe e se mobilize o espírito de cientista/cidadão, para que os atuais vetores da doença de Chagas deixem de sê-lo e se mantenham restritos aos seus ecótopos naturais, não encontrando frestas para procriar. Aliando-se a isso, é necessária a criação de ambientes educacional, social e humanamente saudáveis, mediante uma atuação integrada e sinérgica entre as comunidades rurais, científicas e políticas para a consolidação, aplicação e reavaliação de todo o conhecimento gerado desde 1948 até os resultados finais da campanha de controle de T. infestans (Silveira \& Vinhaes, 1999; Dias, 2006). Assim poderemos atuar e vencer os novos desafios que já se apresentam.

\section{REFERÊNCIAS}

ALMEIDA, C. E. et al. Monitoring the domiciliary and peridomiciliary invasion process of Triatoma rubrovaria in the state of Rio Grande do Sul, Brazil. Memórias do Instituto Oswaldo Cruz, 95: 761-768, 2000.

ALMEIDA, C. E.et al. Could Triatoma sherlocki be vectoring Chagas disease in small mining communities in Bahia, Brazil? Medical and Veterinary Entomology, 2009.

BÉRENGER, J. M. \& BLANCHET, D. A new species of the genus Panstrongylus from French Guiana (Heteroptera; Reduviidae; Triatominae). Memórias do Instituto Oswaldo Cruz, 102: 733-736, 2007.

BRICEÑO-LEÓN, R. \& GALVÁN, M. J. The social determinants of Chagas disease and the transformations of Latin America. Memórias do Instituto Oswaldo Cruz, 102: 109-112, 2007.

CHAGAS, C. Nova tripanossomíase humana: estudos sobre a morfologia e o ciclo evolutivo do Schizotrypanum cruzi n. gen. n. sp., agente etiológico de nova entidade mórbida do homem. Memórias do Instituto Oswaldo Cruz, 1: 159-218, 1909.

COSTA, J. et al. The epidemiologic importance of Triatoma brasiliensis as a Chagas disease vector in Brazil: a revision of domiciliary captures during 1993-1999. Memórias do Instituto Oswaldo Cruz, 98: 443-449, 2003.

COSTA, J. M. \& FÉLIX, M. Triatoma juazeirensis sp. nov. from the state of Bahia, Northeastern Brazil (Hemiptera: Reduviidae: Triatominae). Memórias do Instituto Oswaldo Cruz, 102: 87-90, 2007.

COSTA, J. M.; ARGOLO, A. M. \& FÉLIX, M. Redescription of Triatoma melanica Neiva \& Lent, 1941, new status (Hemiptera: Reduviidae: Triatominae). Zootaxa, 1.385: 47-52, 2006.

COURA, J. R. O falso dilema sobre a luta antivetorial e as perspectivas de controle da doença de Chagas no Brasil: BHC ou BNH? Cadernos de Saúde Pública, 9: 514-518, 1993.

COURA, J. R.; BARRETT, T. V. \& NARANJO, M. A. Ataque de populações humanas por triatomíneos silvestres no Amazonas: uma nova forma de transmissão chagásica? Revista da Sociedade Brasileira de Medicina Tropical, 27: 251-253, 1994.

DEANE, M. P. Ocorrência do Trypanosoma conorrhini em 'barbeiros' e em rato na cidade de Belém, Pará, e seu cultivo em meio de NNN. Revista do Serviço Especial de Saúde Pública, 1: 433-448, 1947. 
DIAS, E. Profilaxia da doença de Chagas: resumo das principais atividades do Centro de Estudos do Instituto Oswaldo Cruz em Bambuí, MG. Brasil Médico, 60: 161-163, 1946.

DIAS, E. \& PELLEGRINO, J. Alguns ensaios com o gammexane no combate aos transmissores da doença de chagas. Brasil Médico, 62: 185-191, 1948.

DIAS, E. \& ZELEDON, R. Infestação domiciliária em grau extremo por Triatoma infestans. Memórias do Instituto Oswaldo Cruz, 53: 473-486, 1955.

DIAS, J. C. P. Doença de Chagas: sucessos e desafios. Cadernos de Saúde Pública, 22: 20, 2006.

DIOTAIUTI, L. et al. Avaliação do programa do controle vetorial da doença de Chagas em Minas Gerais, Brasil, com referência especial ao Triatoma sordida. Boletín de la Oficina Sanitaria Panamericana, 118: 211-219, 1995 .

FORERO, D.; WEIRAUCH, C. \& BAENA, M. Synonymy of the reduviid (Hemiptera: Heteroptera) genus Torrealbaia (Triatominae) with Amphibolus (Harpactorinae), with notes on Amphibolus venator (Klug, 1830). Zootaxa, 670: 1-12, 2004.

FREITAS, J. L. P. et al. Resultado do combate intenso dos triatomíneos domiciliares em uma área restrita do estado de São Paulo (distrito de Cássia de Coqueiros, município de Cajuru). In: CONGRESSO INTERNACIONAL SOBRE DOENÇA DE CHAGAS, 1959. Rio de Janeiro: Anais..., 1959. v. II.

FREITAS, S. P. C.; FREITAS, A. L. C. \& GONÇALVES, T. C. M. Ocorrência de Panstrongylus lutzi (Neiva \& Pinto, 1923) (Hemiptera: Triatominae), em três municípios do estado do Ceará, Brasil. Revista de Saúde Pública, 38: 579-580, 2004.

GALVÃO, C. \& ÂNGUlO, V. M. Belminus corredori, a new species of Bolboderini (Hemiptera: Reduviidae: Triatominae) from Santander, Colombia. Zootaxa, 1.241: 61-68, 2006.

GALVÃO, C. et al. A checklist of the current valid species of the subfamily Triatominae Jeannel, 1919 (Hemiptera, Reduviidae) and their geografical distribution, with nomenclatural and taxonomic notes. Zootaxa, 202: 1-36, 2003.

GONÇALVES, T. C. M. et al. An investigation on the ecology of Triatoma vitticeps (Stål, 1859) and its possible role in the transmission of Trypanosoma cruzi, in the locality of Triunfo, Santa Maria Madalena municipal district, state of Rio de Janeiro, Brazil. Memórias do Instituto Oswaldo Cruz, 93: 711-717, 1998.

LENT, H. \& WYGODZINSKY, P. Revision of the Triatominae (Hemiptera, Reduviidae), and their significance as vector of Chagas' disease. Bulletin of the American Museum of Natural History, 163: 123-520, 1979.

LIMA, V. et al. Chagas disease by Trypanosoma cruzi lineage I in hunter-gatherer ancient population in Brazil. Emerging Infectious Diseases, 14: 1.001-1.002, 2008.

MARSDEN, P. D. et al. Los 13 primeros años del control de la enfermedad de Chagas en Mambaí, Goiás, Brasil, 1980-1992. Boletín de la Oficina Sanitaria Panamericana, 116: 111-117, 1994.

MARTINEZ, E. et al. Triatoma boliviana sp. n. de los valles subandinos de La Paz, Bolivia (Hemiptera: Reduviidae: Triatominae), similar a Triatoma nigromaculata Stål, 1859. Boletín del Instituto de Investigación en Salud y Desarrollo, 3: 1-11, 2007.

NEGHME, A. \& SCHENONE, H. 1962. Enfermedad de Chagas en Chile: veinte años de investigación. In: CONGRESSO INTERNACIONAL SOBRE DOENÇA DE CHAGAS, 1959, Rio de Janeiro. Anais..., 3: $1.069-1.105$.

NEIVA, A. Informações sobre a biologia de Conorrhinus megistus. Memórias do Instituto Oswaldo Cruz, 2: 206-212, 1910 .

PELLI, A. et al. Population parameters for Triatoma sordida Stål, 1859: the most frequent vector for Chagas disease in the Triangulo Mineiro (Heteroptera, Triatominae). Revista da Sociedade Brasileira de Medicina Tropical, 40: 25-28, 2007.

ROMAÑA, C. \& ABALLOS, J. W. Acción del ‘Gamexanne’ sobre los triatomídeos: control domiciliario. Anales del Instituto de Medicina Regional de Tucumán, 2: 95-106, 1948. 
SANDOVAL, C. M. et al. Belminus ferroae n.sp. from the Colombian north-east, with a key to the species of the genus (Hemiptera: Reduviidae: Triatominae). Zootaxa, 1.443: 55-64, 2007.

SILVA, L. J. A doença de Chagas no Brasil: indícios de sua ocorrência e distribuição até 1909. Revista do Instituto de Medicina Tropical de Säo Paulo, 27: 219-223, 1985.

SILVEIRA, A. C. \& VINHAES, M. C. Elimination of vector-borne transmission of Chagas disease. Memórias do Instituto Oswaldo Cruz, 94, supl. I: 405-411, 1999.

SOUZA, R. C. M. et al. Population dynamics of Triatoma vitticeps (St 1, 1859) in Itanhomi, Minas Gerais, Brazil. Memórias do Instituto Oswaldo Cruz, 103: 14-20, 2008.

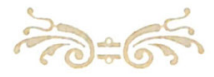

\title{
BHC, os Inseticidas como Ferramenta Central no Controle da Doença de Chagas
}

\author{
Marcelo Gustavo Lorenzo \\ Laboratório de Triatomíneos e Epidemiologia da Doença de Chagas \\ Centro de Pesquisas René Rachou/Fiocruz
}

\section{BREVE RESENHA HISTÓRICA}

O trabalho em que Carlos Chagas descreve o ciclo, os sintomas e o principal mecanismo de transmissão do Trypanosoma cruzi, publicado em 1909, e outros que seguiram a saga evidenciaram a séria problemática que representava a tripanossomíase americana e suas diferentes facetas. Desde aquela data, passaram-se quase quarenta anos para que fosse possível começar a desenvolver o lado técnico da metodologia central de combate à doença de Chagas: a borrifação de inseticidas sintéticos objetivando a eliminação dos insetos vetores. Essa limitação respondeu a fatores históricos que são brevemente analisados aqui.

Os historiadores têm relatado o uso de pesticidas desde a época de Homero, na Grécia, que recomendava a queima de enxofre nas casas. Plínio, o Velho (23-79 d.C.), registrou a maioria dos primeiros usos de inseticidas na sua História Natural. Mas até o início da II Guerra Mundial (1939), a variedade de inseticidas limitava-se a diversos produtos contendo arsênico, óleos de petróleo, nicotina, piretro de Chrysanthemum, rotenona, enxofre, cianeto de hidrogênio etc. Durante a II Guerra Mundial foi que se iniciou a era da química moderna, com a introdução de um novo conceito no controle de insetos: os inseticidas orgânicos sintéticos, o primeiro dos quais foi o DDT (Ware \& Whitacre, 2004).

Os organoclorados são inseticidas que contêm carbono (daí o nome organo-), hidrogênio e cloro. Hoje, conservam principalmente o interesse histórico, pois somente uns poucos sobreviveram no arsenal de moléculas de utilização atual. O DDT é provavelmente o mais conhecido e notório produ to químico desenvolvido no século XX. É particularmente fascinante o fato de que continua reconhecido como o inseticida mais útil jamais desenvolvido. Mais de dois bilhões de quilos de DDT foram usados no mundo desde o seu lançamento em 1940 
até 1973, quando a Agência para a Proteção Ambiental dos Estados Unidos cancelou todos os seus usos no controle de pragas de alimentos e os demais países desenvolvidos seguiram rapidamente o seu exemplo. O DDT ainda é utilizado com efetividade no controle de malária em vários países do chamado Terceiro Mundo. Paul Müller, entomólogo suíço, recebeu o Prêmio Nobel de Medicina em 1948 por sua descoberta, em 1939, desse produto que permitiu salvar muitas vidas mediante o controle de vetores da malária, febre amarela e muitas outras doenças (Müller, 1948).

O hexaclorociclohexano (BHC), conhecido também como hexaclorobenzeno, teve suas propriedades inseticidas descobertas em 1940 por entomologistas franceses e britânicos. No seu grau técnico apresenta cinco isômeros: alfa, beta, gama, delta e épsilon. Surpreendentemente, somente o isômero gama tem propriedades inseticidas. Conseqüentemente, este isômero foi isolado durante a sua produção e vendido como o inseticida inodoro Lindane. O hexaclorobenzeno ou Gammexane foi, a princípio, registrado comercialmente ao final da década de 30. Após quase sete décadas, em 2002, a Agência Estadunidense para a Proteção Ambiental (EPA) suspendeu seu uso em todos os processos relacionados com a produção de comida. Em 2009, o Lindane foi incluído na Convenção de Estocolmo (Programa das Nações Unidas para o Meio Ambiente) para produtos orgânicos poluentes persistentes, e sua produção e uso foram banidos em escala global (Stockholm Convention..., 2009).

\section{Surgem oportunidades}

No fim da década de 1940, a possibilidade de testar um produto clorado comercial é oferecida pela Imperial Chemical Industries, um dos maiores produtores mundiais de substâncias químicas, parte de um conglomerado holandês que incluía a Nobel Industries, a Brunner, Mond and Co., a United Alkali Co. e a British Dyestuffs Corporation. O produto, denominado Gammexane, podia ser dissolvido em água e borrifado em superfícies às quais se desejara proteger. De fato, Busvine e Barnes (1947) demonstraram em ensaios de laboratório que o hexaclorociclohexano era mais efetivo que o DDT para matar vários tipos de artrópodes praga, dentre eles Rhodnius prolixus. No ano seguinte, Dias e Pellegrino (1948) relataram em sua histórica publicação que a aplicação de Gammexane por meio da borrifação de paredes de taipa infestadas com Triatoma infestans era altamente eficiente para eliminar esses insetos. Pioneiramente, esses autores escolheram avaliar o produto em casas da região rural da cidade mineira de Bambuí, $M G$, área previamente caracterizada como endêmica pelos estudos realizados por pesquisadores do Centro de Estudos e Profilaxia da Moléstia de Chagas, posto avançado do Instituto Oswaldo Cruz.

\section{Os detalhes técnicos e suas conseqüências históricas}

Nesse trabalho, Dias e Pellegrino (1948) realizaram dez experimentos independentes para testar as diversas perguntas necessárias e relevantes para a avaliação de um método triatomicida. Os trabalhos tiveram grande mérito técnico e originalidade; foram escolhidas condições reais para os estudos, realizados em paredes de taipa, inclusive em casas inteiras construídas com esse material e habitadas por famílias. Todos os experimentos foram desenvolvidos sob condições ambientais naturais, expondo as moléculas em estudo aos verdadeiros efeitos climáticos e físicos que elas deveriam suportar para serem ferramentas válidas.

Em seu primeiro experimento, expondo uma simples parede de taipa que apresentava um número controlado de triatomíneos em um dos lados e Gammexane, aplicado com uma bomba manual, do outro, os autores demonstram que esse composto era altamente tóxico para T. infestans, o principal vetor da doença de Chagas. Ressaltavam a importância da aplicação de 
uma pulverização fina, para evitar a penetração da substância e promover sua permanência na superfície. Subseqüentemente, Dias e Pellegrino mostram, em seu artigo, que é relevante afetar os triatomíneos nos seus esconderijos, dos quais dificilmente saem nas horas em que os inseticidas são aplicados (Lazzari \& Lorenzo, 1998; Ferreira, 2009; Vitta, 2009). Os dados apresentados demonstravam, de fato, que o BHC apresentado em doses de $1 \mathrm{~g} / \mathrm{m}^{2}$ era capaz de matar os insetos quando estes saíssem dos refúgios, mesmo horas depois da aplicação. Doses menores promoviam mortalidade parcial e eram, portanto, insuficientes, segundo os autores. O trabalho desenvolvido em Bambuí já evidenciava claramente a relevância do efeito residual das moléculas xenobióticas. Os resultados mostravam que a eficiência do gammexane, expressa pelo seu poder letal, diminuía com o tempo. E que doses altas de hexaclorociclohexano perdiam sua capacidade triatomicida após períodos longos.

Ressalta-se que os dados apresentados por Dias e Pellegrino (1948) mostravam claramente que o Gammexane apresentava efeito maior sobre insetos adultos do que sobre ninfas. De maneira semelhante ao demonstrado por Busvine e Barnes (1947) em experimentos de laboratório com $R$. prolixus, Dias e Pellegrino puseram em evidência que o hexaclorociclohexano promovia mortalidade muito mais alta em $T$. infestans que o DDT, mesmo em doses equivalentes. Relatam esses autores que os resultados eram mais efetivos e confiáveis, se na sua avaliação eram utilizados agentes desalojantes para comprovar infestação residual. Inclusive recomendam utilizar o expurgo combinado com Gammexane e piretro, já que isso gerava maior efetividade, desalojando os insetos com o segundo e promovendo, dessa maneira, sua exposição ao contato com o primeiro. Finalmente, os resultados mostraram claramente a capacidade ovicida praticamente nula do BHC, apesar de relatar a morte das ninfas emergentes ao entrarem em contato com superfícies tratadas.

Na mesma época, Romaña e Ávalos (1948) realizaram testes com uma formulação semelhante de Gammexane em casas de uma região rural da Argentina infestadas por $T$. infestans. Os estudos mostraram resultados semelhantes, o que reforça o mérito desses grupos pioneiros de pesquisadores de dois dos países que viriam a compor a Iniciativa do Cone Sul, muitos anos depois de suas descobertas (Silveira et al., 2002). De fato, Romaña e Ávalos (1948) avaliam que apesar de ter sido relatada a eficácia do Gammexane em oportunidade anterior pelos pesquisadores ingleses anteriormente citados (Busvine \& Barnes, 1947), o fato de os testes terem mostrado efetividade com esse vetor e a falta de um inseticida eficaz contra triatomíneos nas condições naturais justificavam a comunicação dos achados. De maneira semelhante ao observado por Dias e Pellegrino (1948), os autores argentinos testaram potes fumegantes com Gammexane e mostraram que sua eficácia era muito reduzida. E coincidiram também na observação de que é absolutamente necessário retirar todos os objetos acumulados no interior das moradias, revisá-los para detectar a presença de insetos e borrifar móveis e estruturas semelhantes. Adicionalmente, recomendavam a aplicação do inseticida em galinheiros e currais vizinhos às moradias.

\section{CONSEQÜENNCIAS E PERSPECTIVAS}

Como observado por Silveira (2000), foi nesses anos que a eficácia do controle pela borrifação sistemática de casas infestadas tornou os inseticidas a primeira alternativa a ser utilizada para eliminar a transmissão do T. cruzi aos humanos. Como conseqüência, algumas campanhas isoladas foram promovidas a partir de 1950 na Argentina e no Brasil. Posteriormente, a Venezuela iniciou ações de controle com inseticidas em algumas regiōes. 
Mas a continuidade da aplicação consistente e sistemática de inseticidas somente veio a acontecer em grandes áreas de alguns dos países latino-americanos décadas depois dessas descobertas. A causa fundamental foi a absoluta falta de interesse das classes governantes pelas populações pobres rurais, mais uma vez esquecidas e abandonadas à sua própria sorte. Cem anos depois da descoberta, infelizmente essa continua a ser a realidade em importantes áreas do nosso continente. Houve avanços, restam grandes desafios.

\section{REFERÊNCIAS}

BUSVINE, J. R. \& BARNES, S. Observations on mortality among insects exposed to dry insecticidal films. Bulletin of Entomological Research, 38: 80-81, 1947.

CHAGAS, C. Nova tripanossomíase humana: estudos sobre a morfologia e o ciclo evolutivo de Schizotrypanum cruzi n., gen., n., sp., agente etiológico de nova entidade mórbida do homem. Memórias do Instituto Oswaldo Cruz, 1: 159-218, 1909.

DIAS, E. \& PELLEGRINO, J. Alguns ensaios com o 'Gammexane' no combate aos transmissores da doença de Chagas. Brasil Médico, 62: 185-191, 1948.

FERREIRA, R. A. A Procura do Hospedeiro e Escolha do Sítio de Picada por um Vetor da Doença de Chagas, 2009. Tese de Doutorado, Rio de Janeiro: Centro de Pesquisas René Rachou, Fundação Oswaldo Cruz.

LAZZARI, C. R. \& LORENZO, M. G. Activity pattern with relation to refuge exploitation and feeding in Triatoma infestans (Hemiptera: Reduviidae). Acta Tropica, 70(2): 163-170, 1998.

MÜLLER, P. Dichloro-diphenyl-trichloroethane and newer insecticides. Nobel Lecture, 1948.

ROMAÑA, C. \& ÁVALOS, J. W. Acción del 'Gamexanne' sobre los triatomídeos: control domiciliario. Anales del Instituto de Medicina Regional de Tucumán, 2: 95-106, 1948.

SILVEIRA, A. C. Situação do controle da transmissão vetorial da doença de Chagas nas Américas. Cadernos de Saúde Pública, 16, supl.: 35-42, 2000.

SILVEIRA, A. C. et al. O Controle da Doença de Chagas nos Países do Cone Sul da América. Uberaba: Faculdade de Medicina do Triângulo Mineiro, 2002.

STOCKHOLM CONVENTION on Persistent Organic Pollutants, 2009. Disponível em: <chm.pops. int >. Acesso em: 30 maio 2009.

VITTA, A. C. R. Comportamento Sexual de Triatoma brasiliensis (Heteroptera/ Reduviidae), 2009. Tese de Doutorado, Rio de Janeiro: Centro de Pesquisas René Rachou, Fundação Oswaldo Cruz.

WARE, G. W. \& WHITACRE, D. M. The Pesticide Book. 6. ed. Willoughby, Ohio: Meister Media Worldwide, 2004. 